\title{
Price variation and transmission in beans consuming market of Southwest, Nigeria
}

\author{
Olanrewaju Olaniyi Omosehin ${ }^{1 *}$; Babatunde Peter Ekundayo ${ }^{2}$; Oluyede \\ Adeleke Aturamu ${ }^{3}$; Adewale Isaac Olutumise ${ }^{4}$ \\ ${ }^{1), 2)}$ Federal University of Technology, Akure, Nigeria \\ ${ }^{3)}$ College of Education, Ikere-Ekiti, Nigeria \\ 4) Adekunle Ajasin University, Akungba-Akoko, Ondo State, Nigeria \\ *To whom correspondence should be addressed. Email: omosehinolaniyi@ gmail.com

\begin{tabular}{|l|l|l|l|l|}
\hline DOI: & Received: & Revised: & Accepted: & Published: \\
10.22437/ppd.v8i6.11018 & 01.11 .2020 & 23.01 .2021 & 24.01 .2021 & 01.02 .2021 \\
\hline
\end{tabular}

\begin{abstract}
Nigeria's bean market is still characterized by inefficient and weak integration due to inadequate price information and market infrastructure. Therefore, the study investigates the price variation and transmission of beans markets in Nigeria's Southwest region. The study employed an average monthly price of white and brown beans in rural and urban markets spanning March 2014 to July 2019. Coefficient of variation (CV), Augmented Dickey-Fuller (ADF), Johansen co-integration test and Granger-Causality tests were the analytical tools used for the analysis. The results of $\mathrm{CV}$ indicated a spike variation of beans prices over the periods. Urban brown beans experienced the lowest variability of $1.56 \%$ in 2015 , while rural brown beans experienced the highest variability of $30.03 \%$ in 2014 . The co-integration test established a long-run dynamic between bean products of different varieties in the same market. However, it failed in the same products in different markets using a bivariate co-integration test. The multivariate co-integration test's results affirmed that bean markets are strongly linked together in the long-run. The results of Granger-causality showed uni-directional and bi-directional causalities in the beans markets. Rural white beans assumed the lead position and formed the major price transmission in the beans' markets in the area. Therefore, for more efficiency in the beans' rural and urban markets, the government should design appropriate market strategies such as accessible market information and infrastructures.
\end{abstract}

Keywords: Beans, Cointegration, Markets, Nigeria, Prices

JEL Classification: E21, E32, G14, P22

\section{INTRODUCTION}

Nigeria has favorable weather for cowpea's ((Vigna unguiculata (L.) Walp.) growth and production, popularly known as beans. It is one of the common and cheap food crops that have inelastic demand in Nigeria's markets. Its potential health benefits in terms of protein content and different forms it can be processed into makes the 
consumption of beans affordable staple food in most homes (Aguilera et al., 2013; Muranaka et al., 2016).

Nigeria is the largest producer and consumer of beans globally, and its share is about $46 \%$ of the world's production (IITA, 2019 and FAOSTAT, 2019). Producers worldwide face dramatic variations in the prices, making price a key factor in the supply and demand for goods as in the beans market.

According to Adenegan et al. (2017), price variation creates a profitable avenue that attracts market actors. However, the bone of contention here is the extent of price elasticity, which determines the level of market integration across space. Therefore, several factors such as production seasonality, natural shocks, bargaining power, and responsive capability to price changes have been identified as the main causes of price volatility in agricultural commodity markets (Akpan et al., 2014). Price insecurity and external influences by unofficial actors are also responsible for the price variation (Da Cunha and Wander, 2014).

According to Saka et al. (2018), beans product is affordable and nutritional compared to other food crops in the market. It makes its demand outgrows the market supply and is responsible for the beans product's price skyrocketing. Again, some other factors such as distance, poor road network, seasons, and pest infestation are also responsible for a decline in beans' supply to the market. The scarcity of the beans product causes unexpected shock to both final product sellers and consumers.

As it is also applicable to other agricultural goods, beans' price tends to come down during harvesting periods as there is a glut of beans in the market but goes up during the offseason. Many intermediaries within the beans' value chain hamper the price symmetry between producers and consumers in the market (Da Cunha and Wander 2014). All these calls for an urgent need to tackle the disparity in bean prices between urban and rural markets in producing areas and consuming Nigeria regions.

Many developmental policies on agriculture and research studies on cowpea (beans) have been geared toward production and profitability from the perspective of the producers (farmers) (Mafimisebi, 2012; Mafimisebi et al., 2014). It was observed that little attention is given to research and development in the price mechanism and marketing system, especially in the product market. It implies a dearth of information on the competitiveness and market integration of bean products in Nigeria that needs to be explored for sustainable development.

The few studies carried out on beans markets were from the other regions of Nigeria, but Akpan et al. (2014) and Adenegan et al. (2017) are similar to this study. The difference is that Akpan et al.'s studies were carried out in the South-south region and measured the price integration of maize and beans in rural and urban markets but failed to examine market integration based on the varieties of beans (white and brown). Likewise, Adenegan et al. (2017) only estimated price integration based on one variety (brown beans) in the selected national market but failed to estimate the aggregate comovement of the brown bean prices between rural and urban markets. The authors also failed to examine the effect of white beans' price on the price transmission between and among the markets.

This study's uniqueness measures price transmission on the aggregate level between rural and urban markets. Unlike other studies, the two common and popular varieties (white and brown beans) are fully included in the model. It is expected to give more insights into how marketers can accurately predict price formation and transmission. Against this background, the study critically examined price variation and 
transmission in the beans consuming market in Nigeria's Southwest region. The study specifically determines the extent of price variability of beans prices in the rural and urban markets in the study area, examine the long-run relationship between rural and urban prices for both varieties, and identifies price formation and transmission in both markets and varieties.

\section{METHODS}

\section{Study area and sources of data}

The study was carried out in the Southwest region of Nigeria, and the region comprises six States. The region is mainly consuming beans in Nigeria, thereby creating sales points for the producing States. Ondo State was selected for this study because of data availability, its strength in consumption, and the beans market's economic viability. Ondo State has eighteen (18) local government areas with a population of 3,441,024 (NPC, 2006). The study used average monthly prices of beans spanning the periods of 65 observations (March 2014 to July 2019). The data were sourced from the Ondo State Bureau of Statistics for urban and rural markets.

\section{Analytical tools and model specifications}

Coefficient of variation (CV). It is a statistical measure of the dispersion of data points around the mean. It measures the extent of variability of the data set concerning the mean of the population.

Unit Root Test. The data (beans prices) were subjected to a unit root test using Augmented Dickey-Fuller (ADF). It is necessary in order to check the order of stationary and the possibility of spurious regression. According to Juselius (2006), a stationary series is one with mean and variance values that will not vary with the sampling period, while a non-stationary series is the one that will exhibit a time-varying mean and variance. The unit root test was checked for integration either at the level I (0) or at the first difference, I (1).

The framework of ADF is based on the equation (1):

$$
\Delta \mathrm{P}_{\mathrm{t}}=\boldsymbol{\alpha}+\beta \mathrm{P}_{\mathrm{t}-1}+\gamma \mathrm{T}+\sum_{k=1}^{n} \delta k \Delta P_{t}-k+\mu_{\mathrm{t}}
$$

Where $\mathrm{P}_{\mathrm{t}}$ is the beans prices series being investigated, $\Delta$ is the first difference operator, $\mathrm{T}$ is time trend variable, $\mu_{\mathrm{t}}$ represents zero mean, serially uncorrelated, random disturbances, $k$ is the lag length; $\boldsymbol{\alpha}, \beta, \gamma$ and ${ }^{\delta k}$ are the coefficient of the vectors.

The unit root test was carried out under the null hypothesis $\beta=0$ against the alternative hypothesis of $\beta<0$ (Mafimisebi et al., 2014).

Johansen Cointegration test. The long-run relationship between rural and urban prices of white and brown beans markets in the State was examined by the cointegration test developed by Johansen and Juselius (1990). If two series are individually stationary at the same order, Johansen and Juselius (1990) and Juselius (2006) model can be used to estimate the long-run cointegrating vector, and it can be stated as:

$$
\Delta \mathrm{P}_{\mathrm{t}}=\boldsymbol{\alpha}+\sum_{i=1}^{k-1} \Gamma i \Delta P t-1+\Pi \mathrm{Pt}-1+\mu_{\mathrm{t}}
$$

Where Pt is a $\mathrm{n} x 1$ vector containing the series of interest (bean price series) at the time $(\mathrm{t}), \Delta$ is the first difference operator.

$$
\Gamma i \text { and are nx n matrices of parameters on the } \mathrm{i}^{\text {th }} \text { and } \mathrm{k}_{\mathrm{th}} \text { lag of } \mathrm{P}_{\mathrm{t}} \text {. }
$$




$$
\Gamma i=\left(\sum_{i=1}^{k} A i\right)-I_{g}, \quad \Pi=\left(\sum_{i=1}^{k} A i\right)-I_{g}
$$

Where $I_{g}$ is the identity matrix of dimension $g, \boldsymbol{\alpha}$ is the constant term; $\mu_{\mathrm{t}}$ is $\mathrm{n} \times 1$ white noise vector.

Granger Causality test. To identify price formation and transmission in both urban and rural market pairs, the Granger Causality test was used. It tests the hypothesis for identification of a causal effect of $\beta_{1}$ on $\beta_{2}$. Following Mafimisebi et al. (2014), the causality test error correlation model (ECM) was expressed as:

$$
\Delta \mathrm{P}_{\mathrm{t}}^{\mathrm{i}}=\beta_{0}+\beta_{1} \mathrm{P}_{(\mathrm{t}-1)}^{\mathrm{i}}+\beta_{2} \mathrm{P}_{(\mathrm{t}-1)}+\sum_{k=1}^{m} \delta_{\mathrm{k}} \Delta \mathrm{P}_{(\mathrm{t}-\mathrm{k})}^{\mathrm{i}}+\sum_{k=1}^{n} \alpha_{\mathrm{h}} \Delta \mathrm{P}_{(\mathrm{t}-\mathrm{h})}+\mu_{\mathrm{t}}
$$

Let $m$ and $n$ denote the number of lags determined by Akaike Information Criterion (AIC). The rejection of the null hypothesis was based on the F-statistic that $a_{h}=0$ for $h$ $=1,2 \ldots . . n$.

Variance decomposition analysis: This was used to ascertain each endogenous variable's dynamic response to a one-period standard deviation shock to the system. It explains the responsiveness of the dependent variables in the VAR to shocks of each of the variables.

\section{RESULTS AND DISCUSSION}

\section{Summary statistics of time series variables}

Table 1 depicts the summary statistics of the monthly time series data used for the study spanning from March 2014 to July 2019 (65 observations). The subject matter examined were: rural bean white (RBW), urban beans white (UBW), rural beans brown (RBB), urban beans brown (UBB).

Table 1. Descriptive statistics of the prices of the bean in rural and urban markets

\begin{tabular}{lcccc}
\hline \multicolumn{1}{c}{ Statistics } & RBW & RBB & UBW & UBB \\
\hline Mean & 314.2692 & 397.6555 & 394.7792 & 515.1415 \\
Median & 316.6700 & 400.0000 & 350.0000 & 450.0000 \\
Maximum & 500.0000 & 600.0000 & 700.0000 & 800.0000 \\
Minimum & 200.0000 & 206.1100 & 197.7800 & 325.0000 \\
Std. Dev. & 80.27151 & 91.59467 & 142.1742 & 152.2140 \\
Skewness & 0.166195 & 0.007582 & 0.873524 & 1.001943 \\
Kurtosis & 2.402839 & 2.285762 & 2.532492 & 2.357300 \\
Jarque-Bera & 1.265019 & 1.382242 & 8.858262 & 11.99419 \\
Probability & 0.531257 & 0.501014 & 0.011925 & 0.002486 \\
Sum & 20427.50 & 25847.61 & 25660.65 & 33484.20 \\
Sum Sq. Dev. & 412385.0 & 536933.3 & 1293664. & 1482823. \\
Observations & 65 & 65 & 65 & 65 \\
\hline
\end{tabular}

Table 1 revealed that the average prices of beans for the periods were $\$ 314.27$, $\$ 397.66$, $\$ 394.78$, and $\$ 515.14$ for RBW, RBB, UBW, and UBB, respectively. The Jarque-Bera coefficient rejects the null hypothesis that errors are normally distributed for the UBW and UBB. All the series were positively skewed and displayed a platykurtic nature of the distribution.

\section{Variability in prices among the beans market}

The variability in the beans' prices (Table 2) was fair for the periods covered by this study. The prices varied from UBB at $1.56 \%$ in 2015 to RBW at $30.03 \%$ in 2014 . The high CV coefficient implies that the prices of beans widely fluctuate in the period. 
The RBW prices experienced high variability in 2014 and 2019 compared to other years. RBB prices highly varied in 2014 and 2019, having $18.20 \%$ and $15.28 \%$, respectively. UBW and UBB prices fluctuate widely in 2018 and 2014, with $16.66 \%$ and $21.64 \%$, respectively.

Table 2. Estimates of the coefficient of variability (CV)

\begin{tabular}{lllll}
\hline Year & RBW & RBB & UBW & UBB \\
\hline 2014 & 30.03 & 18.20 & 12.33 & 21.64 \\
2015 & 6.54 & 4.11 & 6.56 & 1.56 \\
2016 & 5.05 & 5.79 & 7.03 & 3.29 \\
2017 & 4.11 & 3.37 & 5.64 & 1.65 \\
2018 & 12.54 & 11.91 & 16.66 & 18.20 \\
2019 & 20.03 & 15.28 & 12.18 & 6.67 \\
\hline
\end{tabular}

Despite the disparity observed, the change in prices in both markets assumes relatively the same magnitude. The probable reasons for the price fluctuations in some years, such as 2014 and 2019, are due to a hike in fuel prices, translating to high transaction costs. Ondo State is a consuming market, and the demand is always the same throughout the year. The producing states like Kano and Sokoto determine the selling price in the study area. Price variations are always experienced around January/February, the planting period in the producing States.

Similarly, surplus during the harvesting period brings about price dispersion in the area. Other factors responsible for price variations from producing States are seasonality of production, natural shocks, conflicts, terrorist attacks, producers' failure to react to price signals, and bargaining powers. Simultaneously, the effects are felt in the consuming States like the study area (Akpan et al., 2014). As also observed by Akpan et al. (2014) and Shittu et al. (2017), the beans market's average price variation is more of a spike, and they showed a common pattern of fluctuations in rural and urban markets. The trend of both prices, either in rural or urban markets, has small variations when compared with other food prices.

\section{Unit root test of beans prices for rural and urban markets}

The stationary status and order of integration of the bean price series were examined using the standard Augmented Dickey-Fuller (ADF) unit root test as presented in Table 3.

Table 3. Results of stationarity test of price series for rural and urban markets

\begin{tabular}{lllll}
\hline \multirow{2}{*}{ Variable } & \multicolumn{2}{c}{ Price at Level I[0] } & \multicolumn{2}{c}{ Price at the first difference I[1] } \\
\cline { 2 - 5 } & t-statistics & Prob. & t-statistics & Prob. \\
\hline RWB & -2.0775 & 0.254 & $-9.3923 * * *$ & 0.000 \\
RBB & -2.0929 & 0.248 & $-6.6930^{* * *}$ & 0.000 \\
UWB & -1.4785 & 0.538 & $-8.5574 * * *$ & 0.000 \\
UBB & -0.3420 & 0.912 & $-11.4710^{* * *}$ & 0.000 \\
\hline \multirow{*}{*}{$, * *, * * *$ means significant at 10\%, 5\% and 1\% respectively }
\end{tabular}

The results showed that all the price series (RWB, RBB, UWB, and UBB) in both rural and urban markets were stationary at the first difference I(1). As also observed by Mafimisebi (2012) and Adenegan et al. (2017), these findings imply that all the price series were generated by similar stochastic processes and can exhibit the tendency to long-run equilibrium.

\section{Johansen co-integration analyses for beans market price series}

Since all the bean price series were integrated at order one $I(1)$, this justifies and 
fulfill the appropriateness of using the Johansen co-integration test. It should be noted that the null hypothesis of the number of cointegrating equations is rejected if the critical value estimate is less than trace or max-eigenvalues or if the probability level is significant at least $5 \%$ level.

Table 4 showed the bivariate horizontal co-integration test results of the prices of the white and brown beans. Out of the four (4) market price pairs subjected to the test, two (2) market pairs rejected the null hypothesis at a 5\% significant level. It implied that the cointegrating equation's alternative hypothesis favored price pairs of $\mathrm{RWB} / \mathrm{RBB}$ and UWB/UBB. It was confirmed by the estimates of the trace test and maximum eigenvalue that their values are greater than the critical value.

Table 4. Bivariate Cointegration Tests for Rural and Urban Markets

\begin{tabular}{lcccc}
\hline Price pairs & $\begin{array}{c}\text { Trace test } \\
\text { statistics }\end{array}$ & $\begin{array}{c}0.05 \text { critical } \\
\text { value }\end{array}$ & $\begin{array}{c}\text { Maximum } \\
\text { eigenvalue }\end{array}$ & $\begin{array}{c}0.05 \text { critical } \\
\text { value }\end{array}$ \\
\hline RWB/RBB & $38.704^{* *}$ & 15.495 & $35.713^{* *}$ & 14.265 \\
UWB/UBB & $25.771^{* *}$ & 15.495 & $23.160^{* *}$ & 14.265 \\
RWB/UWB & 15.336 & 15.495 & 14.124 & 14.265 \\
RRB/UBB & 9.976 & 15.495 & 8.720 & 14.265 \\
\hline
\end{tabular}

This finding implies that $100 \%$ of beans markets in Ondo State were strongly linked together in the rural and urban markets separately, in the long run despite the short run divergence in the markets. Again, Table 5 presented the multivariate cointegration tests for the beans' prices of the rural and urban markets. The results showed at least two cointegrating equations at the 5\% significant level. The test statistics were greater than the critical value. Hence the null hypothesis is rejected in favor of the alternative for both the trace and max-eigenvalues. It still reiterates the fact that the beans products were strongly linked together in the long run.

Table 5. Multivariate co-integration tests for rural and urban markets

\begin{tabular}{lcccc}
\hline Null hypothesis & Trace Statistics & $\begin{array}{c}0.05 \text { Critical } \\
\text { Value }\end{array}$ & $\begin{array}{c}\text { Maximum } \\
\text { eigenvalue }\end{array}$ & $\begin{array}{c}0.05 \text { Critical } \\
\text { Value }\end{array}$ \\
\hline $\mathrm{r}=0$ & $68.904^{*}$ & 47.856 & $38.807^{*}$ & 27.584 \\
$\mathrm{r}=1$ & $30.097^{*}$ & 29.797 & $27.297^{*}$ & 21.132 \\
$\mathrm{r}=2$ & 2.800 & 15.495 & 2.369 & 14.265 \\
$\mathrm{r}=3$ & 0.431 & 3.841 & 0.431 & 3.841 \\
\hline
\end{tabular}

Trace test indicates 2 cointegrating eqn(s) at the 0.05 level

Max-eigenvalue test indicates 2 cointegrating eqn(s) at the 0.05 level

As also observed by Mafimisebi et al. (2014) and Akpan et al. (2014), it implied that there is a presence of market efficiency in the beans market in the study area since market integration is a proxy for marketing efficiency. However, the co-movement of RWB/UWB and RRB/UBB showed marketing inefficiencies over the periods. It implies that RWB and RRBprices exhibit weak exogeneity to their corresponding prices of UWB and UBB, respectively. It showed that there is strong endogeneity, as also reported by Akpan et al. (2014). According to Adenegan et al. (2017), any marketing system's efficiency is determined by the difference in market prices of similar markets. Therefore, there is low market integration between beans of the same variety (white and brown) between rural and urban markets in Nigeria. Akpan et al. (2014) also reported the flow of symmetric market information between the rural and urban markets of beans in their studies in Akwa Ibom State, Southern Nigeria. 


\section{Analysis of variance decomposition}

Table 6 depicts the Vector Autoregression's Variance Decomposition of beans price series employed for this study. RBW variance decomposition results reflected that it accounts for about $100 \%, 82 \%$, and $70 \%$ of the variations in itself in the short-run, medium-term, and long-run, respectively. RBB explains about $10 \%$ variation in RBW in the medium term and $21 \%$ in the long run. Similarly, the response of UBB to variation in RBW in the medium and long run was nearly $3.5 \%$ and $2.7 \%$, respectively. UBW accounts for about $3.7 \%$ and $5.4 \%$ of RBW variation in the medium term and long run, respectively.

Table 6. A variance decomposition for the prices of the bean

\begin{tabular}{|c|c|c|c|c|c|}
\hline $\begin{array}{l}\text { Variance Decomposition of RBW: } \\
\text { Period }\end{array}$ & S.E. & RBW & RBB & UBB & UBW \\
\hline 1 & 32.91831 & 100.0000 & 0.000000 & 0.000000 & 0.000000 \\
\hline 2 & 41.13264 & 99.61785 & 0.001947 & 0.050976 & 0.329229 \\
\hline 3 & 47.95967 & 93.86111 & 2.212733 & 1.402249 & 2.523910 \\
\hline 4 & 52.36487 & 88.33969 & 5.574483 & 3.062108 & 3.023717 \\
\hline 5 & 56.78170 & 82.42044 & 10.36217 & 3.482116 & 3.735277 \\
\hline 6 & 60.80806 & 77.72564 & 14.71343 & 3.360893 & 4.200043 \\
\hline 7 & 64.16154 & 74.79686 & 17.34028 & 3.158117 & 4.704745 \\
\hline 8 & 67.27780 & 72.75242 & 19.21615 & 2.974561 & 5.056868 \\
\hline 9 & 70.06766 & 71.53419 & 20.41557 & 2.825218 & 5.225025 \\
\hline 10 & 72.87861 & 70.46777 & 21.48305 & 2.681189 & 5.367998 \\
\hline $\begin{array}{c}\text { Variance Decomposition of RBB: } \\
\text { Period }\end{array}$ & S.E. & RBW & RBB & UBB & UBW \\
\hline 1 & 37.71696 & 45.31551 & 54.68449 & 0.000000 & 0.000000 \\
\hline 2 & 41.97939 & 52.17290 & 47.78146 & 0.030874 & 0.014772 \\
\hline 3 & 53.52575 & 47.69648 & 45.06051 & 1.108287 & 6.134719 \\
\hline 4 & 57.27878 & 48.96502 & 41.71156 & 3.791951 & 5.531469 \\
\hline 5 & 65.23647 & 47.31569 & 41.90562 & 4.734450 & 6.044232 \\
\hline 6 & 70.22329 & 47.22267 & 41.46957 & 5.706631 & 5.601129 \\
\hline 7 & 76.17057 & 46.07202 & 41.68627 & 6.088481 & 6.153230 \\
\hline 8 & 80.83833 & 45.60359 & 41.55849 & 6.722987 & 6.114934 \\
\hline 9 & 85.53845 & 45.16066 & 41.50599 & 7.094784 & 6.238565 \\
\hline 10 & 89.96363 & 44.87009 & 41.50608 & 7.410753 & 6.213072 \\
\hline $\begin{array}{l}\text { Variance Decomposition of UBB: } \\
\text { Period }\end{array}$ & S.E. & RBW & RBB & UBB & UBW \\
\hline 1 & 29.29530 & 13.39430 & 1.459604 & 85.14609 & 0.000000 \\
\hline 2 & 50.07746 & 10.37583 & 6.719044 & 78.56377 & 4.341353 \\
\hline 3 & 67.76409 & 8.189829 & 12.16895 & 76.16758 & 3.473645 \\
\hline 4 & 81.54421 & 7.617019 & 13.78727 & 74.84941 & 3.746306 \\
\hline 5 & 94.52540 & 6.883915 & 15.63660 & 73.17978 & 4.299709 \\
\hline 6 & 105.5084 & 6.734604 & 15.51760 & 73.37384 & 4.373965 \\
\hline 7 & 115.9222 & 6.365445 & 15.99367 & 73.08058 & 4.560305 \\
\hline 8 & 125.2257 & 6.186535 & 16.02516 & 73.25609 & 4.532209 \\
\hline 9 & 134.1142 & 5.976211 & 16.27031 & 73.11487 & 4.638610 \\
\hline 10 & 142.4042 & 5.856645 & 16.33008 & 73.15628 & 4.656991 \\
\hline $\begin{array}{c}\text { Variance Decomposition of UBW: } \\
\text { Period }\end{array}$ & S.E. & RBW & RBB & UBB & UBW \\
\hline 1 & 40.73535 & 65.23517 & 3.470476 & 1.502921 & 29.79143 \\
\hline 2 & 55.09187 & 65.82614 & 2.239424 & 6.713600 & 25.22084 \\
\hline 3 & 63.93344 & 70.50850 & 3.699116 & 6.387522 & 19.40486 \\
\hline 4 & 68.88452 & 72.00875 & 3.210050 & 5.726988 & 19.05421 \\
\hline 5 & 74.82232 & 73.01172 & 4.337454 & 5.089554 & 17.56127 \\
\hline 6 & 80.16887 & 72.97968 & 4.754689 & 4.837397 & 17.42823 \\
\hline 7 & 85.21769 & 73.21907 & 5.654684 & 4.791502 & 16.33474 \\
\hline 8 & 89.57493 & 73.42971 & 5.892245 & 4.728442 & 15.94960 \\
\hline 9 & 93.84786 & 73.68677 & 6.141169 & 4.683962 & 15.48810 \\
\hline 10 & 98.03934 & 73.81911 & 6.301733 & 4.642154 & 15.23700 \\
\hline
\end{tabular}


The variance decomposition of RBB is accounted for itself at $54.7 \%, 41.9 \%$, and $41.5 \%$ of the variations in the short, medium, and long-run, respectively. Likewise, $45.3 \%, 47.3 \%$, and $44.9 \%$ of the variations in RBB are accounted for by the changes in RBW in the short, medium, and long run, respectively.

The responses of UBB and UBW to the variations in the RBB were very low, with about $7.4 \%$ and $6.2 \%$ in the long-run, respectively. Furthermore, UBB accounts for about $85 \%, 73 \%$, and $73 \%$ of the short, medium, and long-run variations. UBW explains $4.3 \%$ variation in the middle term and $4.7 \%$ variation in the long run. Similarly, the response of RBW to variation in UBB in the short, medium, and long-run were $13.4 \%, 6.9 \%$, and $5.9 \%$, respectively. The changes in RBB account for increased variations of $1.5 \%, 15.6 \%$, and $16.3 \%$ in the short run, medium-term, and long-run, respectively.

UBW reflected significant variations in response to change in the RBW for about $65 \%$, $73 \%$, and $74 \%$ for the short term, medium-term, and long run, respectively. The variance decomposition of UBW accounts for 29.8\%, 17.6\%, and 15.2\% in the short, medium, and long term, respectively

\section{Pairwise Granger Causality tests}

The causal relationship identifying the price formation and transmission in urban and rural beans market pairs were depicted in Table 7 . The decision criteria reject the null hypothesis if the $\mathrm{F}$ statistics' probability value is less than or equal to 0.05 significant level.

The Table results reflected the evidence of causation and exogeneity among prices series of beans varieties in the market. Six (6) out of twelve (12) bean price pairs rejected the null hypothesis of no Granger causality in the study. Two (2) market prices networks exhibited uni-directional (one-way) causality, and they are UWB and RWB, and RBB and UWB. The implication is that there is no causality from the other markets. Likewise, two (2) market price links displayed bi-directional causality (two-way): RBB and RWB, UWB and UBB. The result can be interpreted that RBB granger-caused RWB at 5\% significant level in the first market link, while RWB strongly grangercaused RBB at $1 \%$ significant level in return. The same goes for UWB that grangercaused UBB at a 5\% significant level in the first market link and vice versa.

Table 7. Pairwise Granger Causality tests

\begin{tabular}{|c|c|c|c|c|}
\hline Null hypothesis & F-statistics & Probability & Decision & Direction \\
\hline $\mathrm{RBB} \rightarrow \mathrm{RWB}$ & $2.392 *$ & 0.042 & Reject & \multirow{2}{*}{ Bi-direction } \\
\hline $\mathrm{RWB} \rightarrow \mathrm{RBB}$ & $3.872 * *$ & 0.003 & Reject & \\
\hline $\mathrm{UBB} \rightarrow \mathrm{RWB}$ & 0.729 & 0.629 & Accept & \multirow{2}{*}{ No direction } \\
\hline $\mathrm{RWB} \rightarrow \mathrm{UBB}$ & 0.695 & 0.655 & Accept & \\
\hline $\mathrm{UWB} \rightarrow \mathrm{RWB}$ & $2.362 *$ & 0.045 & Reject & \multirow{2}{*}{ Uni-directional } \\
\hline $\mathrm{RWB} \rightarrow \mathrm{UWB}$ & 0.306 & 0.930 & Accept & \\
\hline $\mathrm{UBB} \rightarrow \mathrm{RBB}$ & 0.724 & 0.632 & Accept & \multirow{2}{*}{ No directional } \\
\hline $\mathrm{RBB} \longrightarrow \mathrm{UBB}$ & 1.593 & 0.171 & Accept & \\
\hline $\mathrm{UWB} \rightarrow \mathrm{RBB}$ & 1.353 & 0.254 & Accept & \multirow{2}{*}{ Uni-directional } \\
\hline $\mathrm{RBB} \rightarrow \mathrm{UWB}$ & $2.247^{*}$ & 0.050 & Reject & \\
\hline $\mathrm{UWB} \rightarrow \mathrm{UBB}$ & $3.213^{*}$ & 0.010 & Reject & \multirow{2}{*}{ Bi-directional } \\
\hline $\mathrm{UBB} \rightarrow \mathrm{UWB}$ & $2.422^{*}$ & 0.041 & Reject & \\
\hline
\end{tabular}

From the results, RWB proved to show strong exogeneity, therefore, occupied the lead position in the beans varieties market in the area. The major price formation and 
transmission in the market are assumed to drive the market for other beans variety's prices in the area. Mafimisebi (2012) also reported that dominated price series always formed efficient price transmission in the market. The result agrees with the findings of Adenegan et al. (2017), who reported the presence of both uni-directional and bidirectional granger causality in the prices of beans in Nigeria markets.

Similarly, Akpan et al. (2014) observed a bi-directional relationship between rural and urban beans markets using the Granger causality test in Akwa Ibom State, Nigeria. Although both markets play a vital role in the beans market, beans always demonstrate a strong integration coefficient when market activities are initiated from the rural market. It agreed with Akpan et al. (2014) and Adenegan et al. (2017).

\section{CONCLUSIONS AND RECOMMENDATIONS}

\section{Conclusions}

The study extensively evaluated the price variations and transmission in beans rural and urban markets in Ondo State, Nigeria. The data used were the average monthly prices from March 2014 to July 2019. The study concluded that beans prices assume relatively the same magnitude with spike variations over the periods. Again, the demand for beans products is the same throughout the year, with little variations in the planting and harvesting periods in the producing States. Moreso, any variation experienced at the producing State is also transmitted into consuming States and therefore cause a change in the prices.

The study also concludes the presence of a long-run dynamic between beans products of different varieties in the same market but failed in the case of the same products in different markets using bivariate co-integration test. The multivariate cointegration test affirmed that bean markets in Ondo State were strongly linked together in the rural and urban markets separately, in the long run, despite the short-run divergence in the markets. There is also evidence of causation and exogeneity among the price series of bean varieties in the market. Rural white beans (RWB) proved to occupy the lead position in the beans varieties market in the area. Therefore, it is the major price formation and transmission in the market which assumed to drive the market for other beans products' prices in the area.

\section{Recommendations}

This study's information is vital for designing market strategies that will bring more efficiency to the beans market. It can be achieved through the availability of functioning and accessible market information units that could smoothen price transmission between rural and urban markets.

The government should make market infrastructure a priority in the State by providing storage facilities and a good transportation system. It can ensure stable fuel price and good rood network, provide a conducive market environment, building strong market surveillance with effective information technology. Again, most especially in the producing States, the insurgence (Boko Haram) and other natural disasters should be reduced to minimal to experience more market integration in the consuming beans market, especially in the Southern regions.

\section{ACKNOWLEDGMENT}

We sincerely thank Dr. (Mrs.) S. Adeniyi for the data input and extraction, and Ondo State Bureau of Statistics to provide data used in this study. 


\section{REFERENCES}

Adenegan, K.O, Bamidele, J.A. \& Nwauwa, L.O.E. (2017). Spatial price linkages of brown cowpea (Vigna unguiculata) in Nigerian National Markets. Review of Market Integration, 8(1\&2): 65-78. DOI: 10.1177/0974929216687885.

Aguilera Y, Díaz MF, Jiménez T, Benítez V, Herrera T, Cuadrado C, Martín-Pedrosa M, \& Martín-Cabrejas MA. (2013). Changes in non-nutritional factors and antioxidant activity during germination of nonconventional legumes. Journal of Agricultural and Food Chemistry, 61, $8120 \quad-\quad 8125$. http://pubs.acs.org/doi/pdf/10.1021/jf4022652.

Akpan, S.B., Udoh, E.J. \& Udo, U. J. (2014). Monthly price analysis of cowpea (beans) and maize in Akwa Ibom State, Southern Nigeria. International Journal of Food and Agricultural Economics, 2(2), 65 - 86.

Da Cunha, C.A. \& Wander, A.E. (2014). Asymmetry in farm-to-retail dry bean price transmission in São Paulo, Brazil; Journal on Chain and Network Science, 14(1), $31-41$.

FAOSTAT. 2019. Cowpea production by countries: Nigeria. Retrieved from: http://www.fao.org/faostat/en/\#data, Accessed $25^{\text {th }}$ March 2020.

Johansen, S. \& Juselius, K. (1990). Maximum likelihood estimation and inference on co-integration with application to the demand for money. Oxford Bulletin of Economic Statistics, 52(2), 231-254.

Juselius, K. (2006). The Cointegrated VAR Model: Methodology and Applications. Oxford University Press.

Mafimisebi, T.E. (2012). Spatial equilibrium, market integration and price exogeneity in dry fish marketing in Nigeria: A vector auto-regressive (VAR) approach. Journal of Economic Finance and Administrative Science, 17(33), 31 - 37. https: doi.org/10.1016/52077-1886(12)70005-7.

Mafimisebi, T.E., Agunbiade, B.O. \& Mafimisebi, O.E. (2014). Price variability, cointegration and exogeneity in the market for locally produced rice: A case study of Southwest Zone of Nigeria. Journal of Rice Research, 2(118), 1 - 6. http://dx.doi.org/10.4172/jrr.1000118.

Muranaka, S. Shono, M., Myoda, T., Takeuchi, J., Franco, J., Nakazawa, Y. Boukar, O. \& Takagi, H. (2016). Genetic diversity of physical, nutritional and functional properties of cowpea grain and relationships among the traits. Plant Genetic Resources, 14, 67 - 76.

National Population Council (NPC). (2006). Nigeria 2006 Population Census

Saka, J.O., Agbeleye, O.A., Ayoola, O.T., Lawal, B.O., Adetumbi, J.A. \& OloyedeKamiyo, Q.O. (2018). Assessment of varietal diversity and production systems of cowpea (Vigna unguiculata (L.) Walp.) in Southwest Nigeria. Journal of Agriculture and Rural Development in the Tropics and Subtropics, 119(2), 43-52. https://doi.org/10.17170/kobra-2018121864.

Shittu, A. M., Akerele, D. \& Haile, M. (2017). Food price spikes and volatility in local food markets in Nigeria. ZEF Discussion Papers on Development Policy, No. 242.

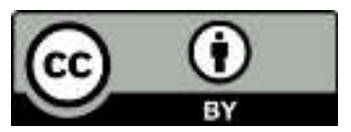

(C) 2021 by the authors. Licensee JPPD, Indonesia. This article is an open-access article distributed under the terms and conditions of the Creative Commons Attribution (CC BY) license (http://creativecommons.org/licenses/by/4.0/). 